\title{
Fatty Acid Metabolism Disorder
}

National Cancer Institute

\section{Source}

National Cancer Institute. Fatty Acid Metabolism Disorder. NCI Thesaurus. Code

C117115.

A group of genetic disorders that result from the inability to produce or use an enzyme required to oxidize fatty acids, resulting in an inability to generate energy from fatty acid sources. 